\title{
Vegetative Growth of Three Southern Highbush Blueberry Cultivars Obtained from Micropropagation and Softwood Cuttings in Two Florida Locations
}

\author{
Silvia R. Marino, Jeffrey G. Williamson', and James W. Olmstead \\ Horticultural Sciences Department, University of Florida, 2113 Fifield Hall, \\ Gainesville, FL 32611-0690 \\ Philip F. Harmon \\ Plant Pathology Department, University of Florida, Gainesville, FL 32611
}

Additional index words. dry weight, propagation, tissue culture

\begin{abstract}
Field performance of southern highbush blueberry (Vaccinium corymbosum $\mathbf{L}$. interspecific hybrids) cultivars Emerald, Jewel, and Primadonna derived from softwood cuttings (SW) and tissue culture (TC) was evaluated in Citra and Haines City, FL, in 2010-12. Both fields were planted in Apr. 2010 on sandy soil amended with pine bark. Plant height and width were recorded at both locations, from which plant canopy volume was calculated. Additionally, whole plants were harvested at planting and after the first growing season, after the first fruit harvest, and after the second growing season. Average plant height and width, number of major canes, and total shoot number were determined at each sampling date. Dry weights for roots, crowns, canes, shoots, and leaves were obtained. Although propagation method affected plant canopy volume during the first season, no effects were observed by the end of the second growing season. At planting and after the first and second growing seasons, TC plants of the three cultivars had more major canes. Total shoot number per plant was greater for TC 'Jewel' at all dates but 'Emerald' TC plants had more shoots only at planting and after the first growing and harvest seasons. Tissue culture resulted in increased plant dry weights of 'Jewel' and 'Emerald' after the first and second growing seasons. There were no significant differences in total number of shoots or plant dry weight between TC and SW-derived 'Primadonna' plants at any point during the study.
\end{abstract}

Blueberries have traditionally been propagated by softwood, semihardwood, or hardwood cuttings. Although plants can be produced at low cost, cuttings from some cultivars have low or very low rooting percentages, particularly when propagated from older, mature plants (Lyrene, 1981; Miller et al., 2004). Therefore, it may take several years to propagate and commercialize newly released cultivars so that significant acreage can be planted (Lyrene, 1980). In contrast, micropropagation has the potential to produce large numbers of plants more quickly than by rooted cuttings, and tissue culture plants can be produced throughout

Received for publication 14 Nov. 2013. Accepted for publication 7 Mar. 2014.

We gratefully acknowledge Fall Creek Farm and Nursery, Island Grove Agricultural Products, and True Blue Plants for plant material and Mixon Family Farms for land donation and assistance in data collection. We thank David Norden for his invaluable help throughout the experiment and are also grateful to James Colee for his contribution to data analysis.

${ }^{1}$ To whom reprint request should be requested; e-mail jgrw@ufl.edu. objective was to compare various vegetative growth traits of southern highbush blueberry cultivars obtained from TC and SW under Florida field conditions. Three commonly planted cultivars were assessed in production regions of Florida that differ primarily by the amount of winter chill accumulation.

\section{Materials and Methods}

Plant material. 'Emerald', 'Jewel', and 'Primadonna' were chosen because they are commonly used in commercial operations in the two test locations. Plants derived from TC were purchased from a nursery in Oregon and plants propagated from SW were purchased from two nurseries in Florida. Plants varied from 11 to $50 \mathrm{~cm}$ tall on arrival across all cultivars and propagation types. The exact age of the plants was unknown, but based on the typical timing for rooting softwood cuttings in Florida and the apparent age and number of growth flushes on the tissue culture plants, the age of the plants was less than 1 year.

Locations and experimental design. The study was conducted at two locations within the major southern highbush blueberry production regions in Florida. The two sites have different average chill hour accumulations. The north site, located at University of Florida Plant Science Research and Education Unit in Citra, FL, receives between 420 to 540 chill hours, whereas the southern location in Haines City (HC), FL, ranges from 110 to $210 \mathrm{~h} /$ year (hours below $7{ }^{\circ} \mathrm{C}$ until $10 \mathrm{Feb}$. in $75 \%$ of winters; Ferguson et al., 2008). 'Jewel', 'Emerald', and 'Primadonna' have estimated chill hour requirements of less than 200, 250, and 400, respectively (Fall Creek Farm and Nursery, 2014). Treatments were arranged in a three $\times$ two factorial (three cultivars and two propagation methods) with five replications arranged in a completely randomized block design with 20-plant plots. The field at Citra was planted on 15 and 16 Apr. 2010 on beds of Arredondo sand (loamy, siliceous well-drained soils), whereas the field at HC was planted on 23 Apr. 2010 in Candler Sand (sand or fine sand, excessively drained soils). Both fields had been amended with incorporated pine bark before planting. At both locations, distance between rows was $3 \mathrm{~m}$ and plant spacing within the row was $0.75 \mathrm{~m}$, and beds were covered with black polypropylene woven fabric for weed control.

Management practices. The field at Citra was irrigated with a single drip tube, which delivered $\approx 374.2 \mathrm{~L} \cdot \mathrm{min}^{-1} \cdot \mathrm{ha}^{-1}$. Irrigation was run in three daily cycles that totaled $45 \mathrm{~min}$ to $1 \mathrm{~h} \cdot \mathrm{d}^{-1}$. A complete liquid fertilizer $(10 \mathrm{~N}-2 \mathrm{P}$ $5 \mathrm{~K}$ with micronutrients) was injected into the irrigation water. The first year, nitrogen $(\mathrm{N})$ rate was $134 \mathrm{~kg} \cdot \mathrm{ha}^{-1}$ from planting until the end of Sept. 2010. During the second year, $100.8 \mathrm{~kg} \cdot \mathrm{ha}^{-1}$ was applied from the end of January until the middle of September. Overhead irrigation was used for freeze protection as necessary, depending on the year. Standard commercial practices were followed for weed, pest, and disease control (Williamson 
et al., 2013). Plants were not pruned the first year but, following standard commercial practices, plants were pruned the second year of the study. In Citra, plants were pruned 1 week after the first harvest season was completed. Plants selected for the June 2011 destructive sampling experiment were flagged and not pruned.

In $\mathrm{HC}$, plants were irrigated with two rows of drip tube, delivering $561.2 \mathrm{~L} \cdot \mathrm{min}^{-1} \cdot \mathrm{ha}^{-1}$. Irrigation was applied in five to eight cycles that totaled between 75 to $120 \mathrm{~min} \cdot \mathrm{d}^{-1}$. A complete $6 \mathrm{~N}-6 \mathrm{P}-3 \mathrm{~K}$ (with micronutrients) liquid fertilizer was injected once a day in spring and fall and three times per day during summer growth flushes for a total of $224 \mathrm{~kg} \mathrm{~N} / \mathrm{ha} /$ year. Plants were hand-pruned at the end of the commercial harvest season (before destructive sampling on June 2011), only removing the old flower spikes while the new vegetative flush was allowed to grow.

Vegetative field measurements. In 2010 and 2011, from July to November, average plant height and width in both directions (spread within and between rows) were measured at monthly intervals. Plant canopy volume was calculated using the formula of an elliptical cone:

$$
V=\left(\pi \cdot d^{2} \cdot h\right) / 6(\mathrm{NASA}, 2010)
$$

where $\mathrm{V}=$ plant canopy volume per tree; $\mathrm{h}=$ plant height, and $\mathrm{d}=$ in-row and within-row average diameter.

Additionally, number of major canes and total number of shoots per plant were recorded from the plants selected to evaluate reproductive growth. Major canes were defined as stems arising from the first $12 \mathrm{~cm}$ above the soil line with a minimum diameter of $8 \mathrm{~mm}$. Shoots that were shorter than $5 \mathrm{~cm}$ and had a diameter of less than $2 \mathrm{~mm}$ were not counted. Data from HC were taken on 10 Dec. 2010 and at Citra on 12 and 14 Jan. 2011. Number of major canes and total shoot number of two plants per plot were recorded. For all measurements, data from the subsample plants were averaged and used for statistical analysis.

Destructive sampling. Whole plants were harvested at four biologically significant points during the study: at the beginning of the experiment (Apr. 2010), after the first season of vegetative growth (Nov./Dec. 2010), after the first harvest (June 2010), and after the second season of growth (Nov. 2011). At planting, 10 representative plants of each cultivar were selected and stems arising $12 \mathrm{~cm}$ from the soil line with a minimum diameter of $8 \mathrm{~mm}$ were recorded as major canes. Lateral branches of each cane were also counted and plants were divided into roots, shoots, and leaves. Roots were washed free of soil and all plant parts were placed in paper bags and dried separately at $60{ }^{\circ} \mathrm{C}$ until constant weights were achieved.

After the first growing season (22 Nov. in $\mathrm{HC}$ and 3 Dec. in Citra), one plant from each plot was excavated. Roots were immediately separated from the tops about at the soil line and bagged separately. Roots were placed in cold storage at $4{ }^{\circ} \mathrm{C}$ until they were washed before drying. Major canes and total number of shoots with a minimum of $2 \mathrm{~mm}$ diameter or $5 \mathrm{~cm}$ in length were counted. All plant organs were separated, dried, and weighed as previously described except that crowns were dried and weighed separately.

Destructive harvests of five plants per treatment were done after the first fruit harvest on 8 June 2011 in Citra and on 14 June 2011 in HC and after the second growing season on 9 Nov. and 28 Nov. 2011 in Citra and $\mathrm{HC}$, respectively. The plant organs were separated, dried, and weighed as described previously.

Statistical analysis. Analysis of variance (ANOVA) was performed using PROC GLM with cultivar and propagation type as main effects (SAS Version 9.2; SAS Institute Inc., Cary, NC). Treatment means were separated using Tukey's honestly significant difference test at $\alpha=0.05$ level of significance. PROC GLIMMIX was used to analyze number of branches and total shoot tips in the second destructive sampling because of unbalanced data. When data transformation was necessary, treatment means were separated based on the transformed data, but means of nontransformed data are presented. Whenever interactions involving location (location by cultivar by propagation and location by propagation) were not significant, means of both locations are reported.

In cases in which the overall effect of propagation was not significant but interactions between main effects were significant (cultivar by propagation, location by propagation, or location by cultivar by propagation), the slice statement was used. This statement produces a separate ANOVA with a $P$ value for propagation method for each cultivar without having to analyze the data for each cultivar separately, which would reduce the df of the analysis (Littell et al., 2002).

Data that did not follow a normal distribution were transformed using the logarithmic function. This included plant volume data from June, July, and Nov. 2010; plant volume; number of canes per plant; and root, shoot, leaf and plant dry weights data before planting (Apr. 2010). From data recorded in June 2010, leaf, shoot, and cane dry weights and from Nov. 2011 leaf and root dry weight data were transformed using the logarithmic function to approximate the normal distribution. Data for leaf and shoot dry weights produced during the first year in the field and data for number of shoots produced between the end of the first and second years were transformed using the logarithmic function as well.

\section{Results}

Plant height and canopy volume. During the first season, propagation effect on plant height was the same across locations. However, the cultivar by propagation interaction for the same period was significant as a result of increased plant height for TC 'Jewel' and reduced plant height for TC 'Primadonna' compared with SW plants (data not shown). Throughout the first season, plants in Citra were larger than in HC (data not shown). Significant interactions of propagation type and cultivar for plant canopy volume were observed throughout the season (Supplemental Table 1 shows main effects and hierarchy of interactions). Canopy volume of TC 'Jewel' plants was significantly larger than for SW plants, whereas the opposite was observed for 'Primadonna'. 'Emerald' TC plants had significantly larger volume in June, July, and November with no significant differences between propagation types during the rest of the first growing season (Table 1).

For much of the second season, plant height was unaffected by propagation method (data not shown). Significant location by cultivar by propagation interaction $(P$ values shown in Supplemental Table 2) from June to Aug. 2011 is evidenced by larger plant canopy volume of 'Emerald' and 'Jewel' TC plants and reduced plant volume of 'Primadonna' TC plants compared with SW plants in HC, whereas in Citra, TC 'Jewel' had larger plant volume only in June without any other effect of propagation method between June and August (Table 2). In Citra, propagation method did not have a significant effect on plant volume of 'Primadonna' at any point during the season. Averaged across locations, 'Emerald' and 'Jewel' plant volumes were greater for TC than SW plants in September and October (Table 3). Conversely, there was no significant effect of propagation type on plant volume of 'Primadonna' plants for the same months. In Nov. 2011, propagation effect on plant canopy volume, across cultivars and locations, was not significant $(P=$ 0.0644).

Number of major canes and total shoots/ plant. TC plants of all cultivars had more major canes at planting (Table 4) and at the end of the first and second growing seasons (Table 5). After the first harvest (June 2011), significant cultivar by propagation interaction is evidenced by increased number of canes for TC 'Emerald' and 'Jewel' plants compared with plants from SW cuttings with no significant effect of propagation method on 'Primadonna'. TC 'Emerald' and 'Jewel' plants had more total shoots per plant at planting and on Dec. 2010 (Fig. 1) and June 2011 (Table 5). Additionally, TC 'Jewel' plants had more shoots per plant at the end of the second growing season. There was no significant difference in total number of shoots per plant between TC and SW 'Primadonna' plants at any point during the study.

Destructive sampling. Plant height and root and shoot dry weights were greater for TC plants than for SW plants for each cultivar at planting (Table 4). Initially, average width of 'Emerald' and 'Jewel' was greater for TC plants than for SW plants, whereas the opposite was observed for 'Primadonna'. Leaf dry weight of TC plants was greater in 'Jewel' but reduced in 'Primadonna' plants compared with SW plants, whereas propagation type 
Table 1. Effect of cultivar and propagation method on plant volume $\left(\mathrm{dm}^{3}\right)$ in 2010 .

\begin{tabular}{lccllll}
\hline Treatment & June & \multicolumn{1}{c}{ July } & \multicolumn{1}{c}{ August } & September & October & November \\
\hline ESW & $7.42^{*}$ & $13.87^{* *}$ & $23.66 \mathrm{NS}$ & $38.69 \mathrm{NS}$ & $37.98 \mathrm{NS}$ & $39.93^{* * *}$ \\
ETC & 10.50 & 25.14 & 35.57 & 62.75 & 58.34 & 63.70 \\
JSW & $2.17^{* * *}$ & $7.06^{* * *}$ & $12.33^{* *}$ & $36.19^{* * *}$ & $36.63^{* * *}$ & $41.70^{* * *}$ \\
JTC & 16.14 & 29.18 & 40.08 & 94.69 & 92.33 & 107.54 \\
PSW & $31.87^{* *}$ & $74.11^{* * *}$ & $99.47^{* * *}$ & $171.95^{* *}$ & $163.59^{*}$ & $168.29 \mathrm{NS}$ \\
PTC & 20.45 & 45.89 & 63.13 & 127.05 & 128.51 & 133.85 \\
\hline
\end{tabular}

$\mathrm{ESW}=$ 'Emerald', softwood cuttings; ETC = 'Emerald', tissue culture; JSW = 'Jewel', softwood cuttings; JTC $=$ 'Jewel,' tissue culture; PSW = 'Primadonna', softwood cuttings; PTC = 'Primadonna', tissue culture.

NS, *,**,** Nonsignificant or significant at $P \leq 0.05,0.01$, or 0.001 between propagation types within a cultivar according to $P$ values from sliced analysis of variance. Data shown are averages of both locations, $\mathrm{n}=10$.

Table 2. Effect of cultivar and propagation method on plant volume $\left(\mathrm{dm}^{3}\right)$ in 2011 at two locations.

\begin{tabular}{|c|c|c|c|c|}
\hline \multirow[b]{2}{*}{ Location } & \multirow[b]{2}{*}{ Treatment } & \multicolumn{3}{|c|}{ Volume $\left(\mathrm{dm}^{3}\right)$} \\
\hline & & June & July & August \\
\hline \multirow[t]{6}{*}{ Citra } & ESW & $108.14 \mathrm{NS}$ & $160.68 \mathrm{NS}$ & $264.31 \mathrm{NS}$ \\
\hline & ETC & 116.09 & 183.60 & 311.24 \\
\hline & JSW & $117.74^{*}$ & $194.73 \mathrm{NS}$ & $318.17 \mathrm{NS}$ \\
\hline & JTC & 170.57 & 239.37 & 400.41 \\
\hline & PSW & $160.18 \mathrm{NS}$ & $264.26 \mathrm{NS}$ & $415.75 \mathrm{NS}$ \\
\hline & PTC & 177.59 & 269.18 & 460.40 \\
\hline \multirow[t]{6}{*}{ Haines City } & ESW & $161.51 * * *$ & $192.15 * * *$ & $259.62 * *$ \\
\hline & ETC & 259.29 & 320.17 & 395.90 \\
\hline & JSW & $161.07 * * *$ & $219.22 * *$ & $333.63 *$ \\
\hline & JTC & 263.95 & 325.87 & 440.48 \\
\hline & PSW & $221.74 *$ & $306.46^{*}$ & $386.15^{*}$ \\
\hline & PTC & 175.12 & 239.35 & 288.76 \\
\hline
\end{tabular}

$\mathrm{ESW}=$ 'Emerald', softwood cuttings; ETC = 'Emerald', tissue culture; JSW = 'Jewel', softwood cuttings; $\mathrm{JTC}=$ 'Jewel,' tissue culture; PSW = 'Primadonna', softwood cuttings; PTC = 'Primadonna', tissue culture.

NS, *,***** Nonsignificant or significant at $P \leq 0.05,0.01$, or 0.001 between propagation types within each location and cultivar, according to $P$ values from sliced analysis of variance, $\mathrm{n}=5$.

Table 3. Effect of cultivar and propagation method on plant volume in Sept., Oct., and Nov. 2011.

\begin{tabular}{lllc}
\hline & \multicolumn{3}{c}{ Volume $\left(\mathrm{dm}^{3}\right)$} \\
\cline { 2 - 4 } Treatment & September & \multicolumn{1}{c}{ October } & November $^{\text {z }}$ \\
\hline ESW & $331.16^{*}$ & $388.00^{*}$ & 439.3 \\
ETC & 446.23 & 500.89 & 522.9 \\
JSW & $445.84^{*}$ & $516.44^{*}$ & 532.0 \\
JTC & 547.29 & 627.97 & 688.1 \\
PSW & $537.34 \mathrm{NS}$ & $631.19 \mathrm{NS}$ & 740.6 \\
PTC & 497.16 & 572.57 & 750.1 \\
\hline
\end{tabular}

${ }^{\mathrm{z} C u l t i v a r}$ by propagation interaction not significan $(P=0.440)$ and propagation effect not significant $(P=0.064)$. Means of both locations are shown to illustrate plant canopy volume at the end of the study.

$\mathrm{ESW}=$ 'Emerald', softwood cuttings; ETC = 'Emerald', tissue culture; JSW = 'Jewel', softwood cuttings; JTC = 'Jewel,' tissue culture; PSW = 'Primadonna', softwood cuttings; PTC = 'Primadonna', tissue culture.

Ns, *,**,*** Nonsignificant or significant at $P \leq$ $0.05,0.01$, or 0.001 between propagation types within a cultivar, according to $P$ values from analysis of variance sliced by cultivar. Data shown are averages of both locations, $\mathrm{n}=10$.

had no effect on 'Emerald' leaf dry weight. 'Emerald' and 'Jewel' TC had greater plant dry weight (data not shown) and plant canopy volume before planting with no effect of propagation type on 'Primadonna' plant dry weight or canopy volume (Table 4).

At the end of the first season (Nov./Dec. 2010), there was no significant effect of propagation type on plant height, plant canopy volume (data not shown), or root dry weight for any of the cultivars at either of the two locations (Table 6). However, significant location by propagation interactions were observed for leaf and cane dry weights. In Citra, TC plants had greater leaf dry weight compared with SW plants $(\mathrm{SW}=110.68 \mathrm{~g}$ vs. $\mathrm{TC}=145.39 \mathrm{~g}, P=0.0413)$ and greater cane dry weight than $\mathrm{SW}$ plants $(\mathrm{SW}=132.23 \mathrm{~g}$ vs. $\mathrm{TC}=184.33 \mathrm{~g}, P=0.0319)$ without a significant difference among propagation types for these variables in HC. 'Emerald' and 'Jewel' TC had more canes, lateral branches, and total number of shoots per plant (Table 5) as well as greater plant width and volume and shoot (data not shown) and plant dry weight compared with SW plants (Table 6). However, propagation type had no significant effect on total number of shoots, volume, or plant dry weight of 'Primadonna' at the end of the first growing season.

In June 2011, 'Emerald' and 'Jewel' TC had significantly greater plant height and canopy volume (data not shown) and plant dry weights compared with SW plants without a significant effect on canopy size or dry weight of 'Primadonna' after $\approx 14$ months of field growth (Table 6). Additionally, root dry weight was greater for 'Emerald' and 'Jewel' TC, whereas for 'Primadonna', greater root dry weight was recorded on SW plants. There was a significant location by propagation interaction for root:shoot ratio: TC plants had smaller root:shoot ratio in Citra $(\mathrm{SW}=$
0.72 vs. TC $=0.45, P \leq 0.0001)$ with no significant difference between propagation types in $\mathrm{HC}(\mathrm{SW}=0.33$ vs. $\mathrm{TC}=0.25, P=$ 0.0645 ). Although TC significantly increased leaf dry weight in both locations, treatment differences were larger in Citra (SW: $59.52 \mathrm{~g}$ vs. TC: $129.7 \mathrm{~g} ; P \leq 0.0001)$ than in HC (SW: $55.6 \mathrm{~g}$ vs. TC: $69.6 \mathrm{~g}, P=0.0011$ ).

After the second year in the field, plant height was not significantly affected by propagation method (data not shown). Conversely, TC plants had larger mean diameter $(\mathrm{SW}=92.22 \mathrm{~cm}$ vs. $\mathrm{TC}=99.12 \mathrm{~cm}, P=$ $0.0384)$ and greater plant volume $(\mathrm{SW}=$ $569.5 \mathrm{dm}^{3}$ vs. TC $=664.2 \mathrm{dm}^{3}, P=0.0399$ ). Cultivar by propagation interaction is shown by increased cane, total shoot (data not shown), and plant dry weights of 'Emerald' and 'Jewel' TC plants but not of 'Primadonna' (Table 6). 'Emerald' and 'Jewel' root dry weights were unaffected by propagation type but TC 'Primadonna' plants had reduced root dry weight compared with SW plants. A significant location by cultivar by propagation type interaction was observed for leaf dry weight; there was no effect of propagation type on any cultivar in Citra, whereas in HC, 'Emerald' TC plants had higher leaf dry weight $(\mathrm{ESW}=80.18 \mathrm{~g}$ vs. $\mathrm{ETC}=134.98$, $P=0.0033$ ) and 'Jewel' TC plants had reduced leaf dry weight compared with SW plants $(\mathrm{JSW}=73.42 \mathrm{~g}$ vs. $\mathrm{JTC}=49.44 \mathrm{~g}, P=$ 0.0381 ) and there was no effect of propagation type on 'Primadonna'.

Increase in cane and total shoot number and dry weights during the first 2 years of field growth. To determine the effect of initial plant size on final vegetative measurements, ANOVA was performed on the difference in measurements taken after one season of field growth (Nov. to Dec. 2010) and measurements taken at planting (Apr. 2010) and on the difference between the end of the first and the end of the second seasons of field growth.

The effect of propagation on plant canopy volume (data not shown) and total number of shoots produced during the first year in the field were not significant (Table 7). Conversely, from planting until the end of the first growing season, TC plants produced more new canes than plants derived from SW ( $\mathrm{SW}=4.80$ vs. $\mathrm{TC}=5.97, P=0.0241)$. Leaf, shoot, and plant dry weights produced by TC 'Emerald' and 'Jewel' plants during the same period were significantly greater than values recorded for SW plants of the same cultivars, whereas propagation effect on the same variables was not significant for 'Primadonna' (Table 7).

Plant canopy volume produced between the end of the first and the second growing seasons was not significantly different between propagation types $(P=0.0937)$. However, TC plants grew more canes $(\mathrm{SW}=1.8 \mathrm{vs}$. $\mathrm{TC}=3.9, P=0.0022)$ and total shoots per plant $(\mathrm{SW}=121.7$ vs. $\mathrm{TC}=150.9, P=$ 0.0114 ). Additionally, TC plants produced more total shoot $(\mathrm{SW}=534.66 \mathrm{~g}$ vs. $\mathrm{TC}=$ $700.92 \mathrm{~g}, P=0.0003$ ) and plant dry weight compared with SW plants $(\mathrm{SW}=1079.12 \mathrm{~g}$ vs. $\mathrm{TC}=1277.78 \mathrm{~g}, P=0.0102)$. 
Table 4. Effect of cultivar and propagation method on initial plant size and dry weights before planting (Apr. 2010).

\begin{tabular}{lcccccccc}
\hline Treatment & $\mathrm{Ht}(\mathrm{cm})$ & Width $(\mathrm{cm})$ & Volume $\left(\mathrm{dm}^{3}\right)$ & Number of canes & Total shoots & Root DW $(\mathrm{g})$ & Shoot DW $(\mathrm{g})$ & Leaf DW $(\mathrm{g})$ \\
\hline ESW & $16.6 \mathrm{~d}^{2}$ & $15.0 \mathrm{c}$ & $2.16 \mathrm{c}$ & $1.0^{* * *}$ & $6.1^{* * *}$ & $1.85 \mathrm{c}$ & $1.88 \mathrm{c}$ & $2.08 \mathrm{~b}$ \\
ETC & $34.2 \mathrm{~b}$ & $19.9 \mathrm{~b}$ & $7.33 \mathrm{~b}$ & 2.3 & 9.3 & $3.17 \mathrm{~b}$ & $4.89 \mathrm{ab}$ & $2.88 \mathrm{~b}$ \\
JSW & $17.2 \mathrm{~d}$ & $10.4 \mathrm{~d}$ & $0.99 \mathrm{~d}$ & $1.0^{* * *}$ & $3.8^{* * *}$ & $1.06 \mathrm{~d}$ & $1.10 \mathrm{~d}$ \\
JTC & $43.6 \mathrm{a}$ & $22.5 \mathrm{~b}$ & $11.89 \mathrm{~b}$ & 2.7 & 12.1 & $7.03 \mathrm{a}$ & $5.93 \mathrm{a}$ \\
PSW & $23.7 \mathrm{c}$ & $28.3 \mathrm{a}$ & $9.99 \mathrm{ab}$ & $1.5^{* *}$ & $9.9 \mathrm{NS}$ & $2.96 \mathrm{~b}$ & $2.57 \mathrm{~b}$ \\
PTC & $37.6 \mathrm{~b}$ & $21.4 \mathrm{~b}$ & $9.06 \mathrm{ab}$ & 2.2 & 11.1 & $4.89 \mathrm{a}$ & $6.09 \mathrm{~b}$ & $5.14 \mathrm{a}$ \\
\hline
\end{tabular}

${ }^{\mathrm{z}}$ Means followed by the same letters within a column indicate no significant differences, Tukey's honestly significant difference test, $\alpha=0.05$. Data shown are averages of both locations.

ESW = 'Emerald', softwood cuttings; ETC = 'Emerald', tissue culture; JSW = 'Jewel', softwood cuttings; JTC = 'Jewel,' tissue culture; PSW = 'Primadonna', softwood cuttings; PTC = 'Primadonna', tissue culture.

Ns, ${ }^{*}, * *, * * *$ Nonsignificant or significant at $P \leq 0.05,0.01$, or 0.001 between propagation types within a cultivar, according to $P$ values from sliced analysis of variance, $\mathrm{n}=10$.

$\mathrm{DW}=$ dry weight.

Table 5. Effect of cultivar and propagation method on the number of major canes and total shoots/plant at three field sampling dates performed during the study.

\begin{tabular}{|c|c|c|c|c|c|c|}
\hline \multirow[b]{2}{*}{ Treatment } & \multicolumn{3}{|c|}{ Number of canes } & \multicolumn{3}{|c|}{$\begin{array}{r}\text { Total shoots/plant } \\
\end{array}$} \\
\hline & Dec. 2010 to Jan. $2011^{z}$ & June 2011 & Nov. 2011 & Dec. 2010 to Jan. $2011^{y}$ & June 2011 & Nov. 2011 \\
\hline ETC & 8.4 & 10.7 & 12.1 & 46.9 & 154.6 & 177.6 \\
\hline PSW & $7.5^{* *}$ & $7.7 \mathrm{NS}$ & $8.4 * *$ & $50.3 \mathrm{NS}$ & $96.4 \mathrm{NS}$ & $148.9 \mathrm{NS}$ \\
\hline PTC & 9.5 & 9.3 & 11.2 & 47.1 & 105.3 & 154.1 \\
\hline
\end{tabular}

${ }^{\mathrm{z}, \mathrm{y}}$ Data obtained from plants selected to evaluate reproductive growth. Number of canes, cultivar by propagation $P=0.0580$; propagation $P<0.0001$.

$\mathrm{ESW}=$ 'Emerald', softwood cuttings; ETC = 'Emerald', tissue culture; JSW = 'Jewel', softwood cuttings; JTC = 'Jewel', tissue culture; PSW = 'Primadonna', softwood cuttings; PTC = 'Primadonna', tissue culture.

Ns, * **, *** Nonsignificant or significant at $P \leq 0.05,0.01$ or 0.001 between propagation types within a cultivar, according to $P$ values from sliced analysis of variance. Data shown are averages of both locations, $\mathrm{n}=10$.
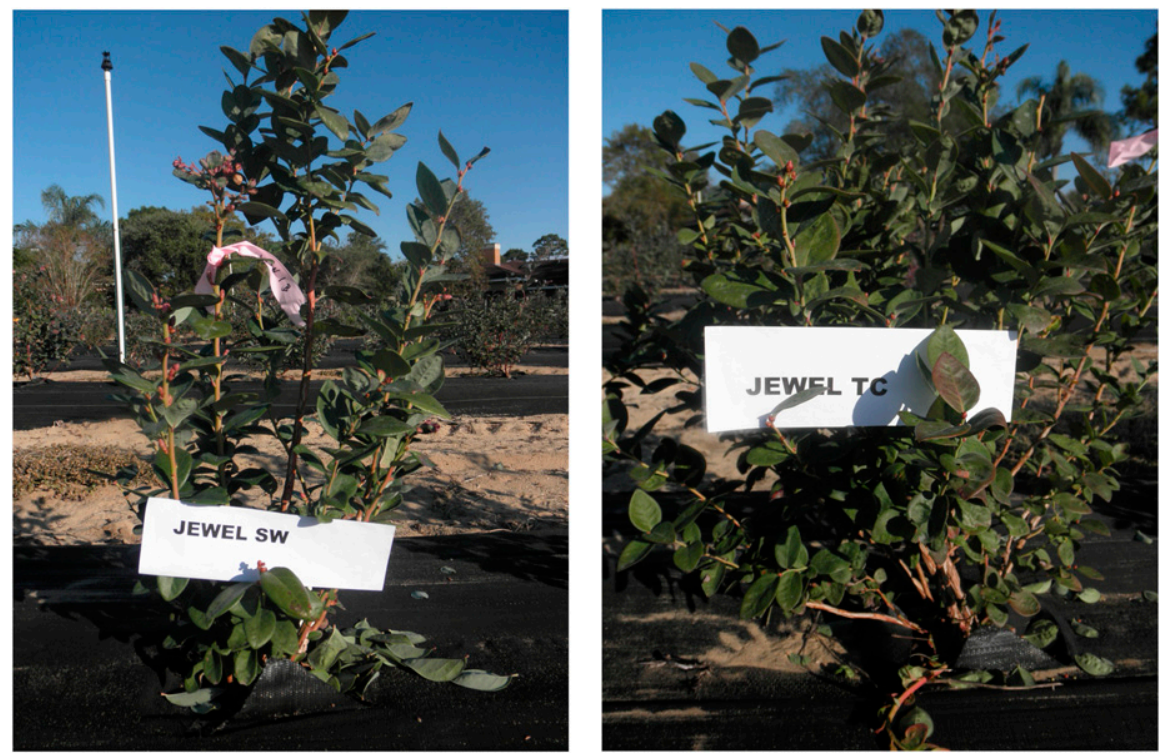

Fig. 1. Effect of propagation method on 'Jewel' plant architecture. Haines City, Dec. 2010. Similar results were observed with 'Emerald' plants from the two propagation methods. JSW = 'Jewel'; softwood cuttings; JTC = 'Jewel', tissue culture.

\section{Discussion}

Differences in plant volume resulting from propagation method were larger at the beginning of the study but tended to decrease during the second year. At the end of the second growing season (Nov. 2011), plant volume was not significantly different between propagation types for any of the cultivars in the study (Table 2). Greater plant canopy volume of TC 'Emerald' and 'Jewel' observed in $\mathrm{HC}$ at the beginning of the second season could be attributed to greater plant width, because there was no significant effect on plant height for most of the second season. Similar results were obtained with lowbush blueberry, where TC plants had greater diameter at ground level than SW plants (Jamieson and Nickerson, 2003)

In addition to soil type and climate variations between our test locations, differences in management practices could have contributed to the differences in plant growth observed between the two locations. The reduced plant dry weights observed in $\mathrm{HC}$ during the second season could be attributed to insufficient chilling (Darnell and Davies, 1990) or the result of differences in climate and cultural practices between the two locations. Smaller plant dry weights recorded at the end of the second season for HC compared with Citra were mostly the result of differences in leaf and root dry weights. Smaller leaf dry weights in $\mathrm{HC}$ may be attributed to insufficient chilling but could also be the result of weather conditions favorable to leaf diseases (causing earlier and greater leaf drop), which were observed to be more prevalent in HC. Reduced root dry weight in $\mathrm{HC}$ compared with Citra may have resulted from differences in leaf number and health or differences in management practices such as irrigation and fertilization.

In June and July of the second year, plants at Citra had reduced plant volume compared with plants in HC (averaged across all levels of the other factors), and there was a significant location by cultivar by propagation interaction. One possible explanation for these differences is that only two of the data plants per plot were harvested for yield data in Citra and the rest of the plants in each plot were not picked almost until the end of the season, whereas in $\mathrm{HC}$, the field was part of a commercial operation and all plants were harvested regularly. Moreover, in Citra, fruit yields were much higher than in $\mathrm{HC}$, adding further to the stress brought on by young plants carrying a heavy cropload, which often results in reduced vegetative growth. Increased plant dry weight of young highbush blueberry cultivars when flower buds were removed has been reported (Strik and Buller, 2005; Williamson and NeSmith, 2007). The hypothesis that 
Table 6. Effect of cultivar and propagation method on plant dry weights in Nov./Dec. 2010, June 2011, and Nov. 2011. ${ }^{2}$

\begin{tabular}{|c|c|c|c|c|c|c|}
\hline \multirow[b]{2}{*}{ Treatment } & \multicolumn{2}{|c|}{ November/Dec. 2010} & \multicolumn{2}{|c|}{$\begin{array}{r}\text { June } 2011 \\
\end{array}$} & \multicolumn{2}{|c|}{$\begin{array}{r}\text { Nov. } 2011 \\
\end{array}$} \\
\hline & Root DW $(g)^{y}$ & Plant DW (g) & Root DW (g) & Plant DW (g) & Root DW (g) & Plant DW (g) \\
\hline$\overline{\mathrm{ESW}}$ & 54.7 & $308.39^{*}$ & $104.02 * *$ & $486.59 * * *$ & $375.90 \mathrm{NS}$ & $1441.40 *$ \\
\hline ETC & 57.1 & 419.41 & 138.44 & 784.85 & 425.30 & 1758.00 \\
\hline JSW & 48.9 & $274.26 * *$ & $73.48 * * *$ & $398.97 * * *$ & $338.76 \mathrm{NS}$ & $1337.45 * * *$ \\
\hline JTC & 48.8 & 407.90 & 123.97 & 892.92 & 402.06 & 1816.83 \\
\hline PSW & 69.2 & $446.54 \mathrm{NS}$ & $138.82 * * *$ & $579.22 \mathrm{NS}$ & $414.45 *$ & $1487.70 \mathrm{NS}$ \\
\hline PTC & 45.1 & 366.47 & 92.31 & 513.62 & 330.97 & 1452.29 \\
\hline
\end{tabular}

${ }^{\mathrm{z} D a t a}$ shown are averages of both locations.

${ }^{\mathrm{y}}$ At the end of the first growing season, propagation effect on root dry weight was not significant $(P=0.1759)$. Cultivar by propagation effect was not significant $(P=0.0903)$.

ESW = 'Emerald', softwood cuttings; ETC = 'Emerald', tissue culture; JSW = 'Jewel', softwood cuttings; JTC = 'Jewel', tissue culture; PSW = 'Primadonna', softwood cuttings; PTC $=$ 'Primadonna', tissue culture.

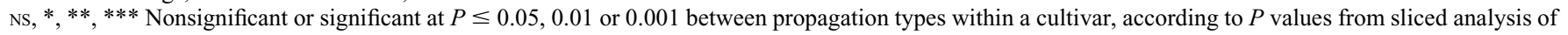
variance, $\mathrm{n}=10$.

$\mathrm{DW}=$ dry weight.

Table 7. Effect of cultivar and propagation method on total number of shoots and leaf, shoot and plant dry weights produced during the first season of field growth. ${ }^{\mathrm{z}}$

\begin{tabular}{lcccc}
\hline & \multicolumn{4}{c}{ Between planting and Nov/Dec. 2010 } \\
\cline { 2 - 5 } Treatment & Total shoots & Leaf DW $(\mathrm{g})$ & Shoot DW $(\mathrm{g})$ & Plant DW $(\mathrm{g})$ \\
\hline ESW & $30.4^{\mathrm{Y}}$ & $67.78^{*}$ & $135.35^{*}$ & $302.58^{*}$ \\
ETC & 43.7 & 95.54 & 202.83 & 408.47 \\
JSW & $48.4 \mathrm{NS}$ & $77.71^{* *}$ & $110.30^{* *}$ & $271.34^{* *}$ \\
JTC & 54.8 & 115.54 & 182.07 & 392.37 \\
PSW & $40.1 \mathrm{NS}$ & $105.57 \mathrm{NS}$ & $196.33 \mathrm{NS}$ & $434.45 \mathrm{NS}$ \\
PTC & 28.3 & 98.25 & 168.77 & 353.51 \\
\hline
\end{tabular}

${ }^{\mathrm{z}}$ Data shown are means of both locations.

${ }^{\text {y }} P=0.064$, between propagation types for 'Emerald', from sliced analysis of variance.

NS, *,**,*** Nonsignificant or significant at $P \leq 0.05,0.01$ or 0.001 between propagation types within a cultivar, according to $P$ values from sliced analysis of variance, $\mathrm{n}=10$.

$\mathrm{ESW}=$ 'Emerald', softwood cuttings; ETC = 'Emerald', tissue culture; JSW = 'Jewel', softwood cuttings; JTC $=$ 'Jewel', tissue culture; PSW = 'Primadonna', softwood cuttings; PTC = 'Primadonna', tissue culture.

$\mathrm{DW}=$ dry weight.

smaller plant volume in Citra compared with HC, in June and July 2011, was a result of the high cropload is also supported by the data from the destructive sampling after harvest (June 2011), where leaf, shoot, and whole plant dry weights were greater in $\mathrm{HC}$, although plants at that location had been pruned before the experiment. Conversely, leaf, total shoot, and plant dry weights were larger in Citra than in $\mathrm{HC}$ at the first destructive sampling (end of 2010) and leaf, root, and plant dry weights were greater at the following sampling date (end of 2011).

Pruning differences between locations may have also contributed to the differences in plant volume between the two locations. Plants in HC were pruned earlier (4 weeks before measurements) than in Citra, where plants were pruned 2 weeks before starting measurements in June 2011. Moreover, differences in pruning style may have also played a role in the location effect on canopy volume. In Citra, manual topping and pruning included removal of canes that did not grow upright and/or originated too close to the soil line. However, in HC, pruning consisted mostly of topping the plants with much lighter cane removal. This can also explain the interaction between treatments and location observed at this point: in Citra, where plants had been pruned just 3 weeks before recording height and width in June 2011, there were less differences in plant volume between propagation types but in $\mathrm{HC}$, where plants had time to grow after light summer pruning and before measurements were taken, we observed larger plant volume of TC 'Emerald' and 'Jewel' plants at the beginning of the second season.

Tissue culture resulted in greater plant dry weight at the end of the second year in the field with 'Emerald' and 'Jewel', which agrees with results obtained in TC lingonberry and blackberry plants (Gustavsson and Stanys, 2000; Swartz et al., 1983). Effect of propagation method on number of laterals also varied among different blackberry cultivars (Swartz et al., 1983). Here, during the first year after planting, TC 'Emerald' plants produced more shoots than plants from SW, whereas there was no difference in the other two cultivars. The greater number of shoots per plant observed in TC 'Jewel' after 1 year may have been the result of differences in plant age or size, between propagation types, at the beginning of the study. Although many of the previous studies done to evaluate field performance of TC and SW plants did not include initial measurements, Grout et al. (1986) reported that TC 'Northblue' plants increased $46 \%$ in size (centimeters per plant) compared with $24 \%$ increase for plants from cuttings under greenhouse growth conditions. At planting, for the present experiment, there were significant differences in plant height, width and canopy volume, and whole plant and certain organ dry weights between propagation methods. Because independence of the covariates (the initial values) with respect to the treatments (the plant itself represents the treatment) was not met (Cochran, 1957; Elashoff, 1969), we could not use analysis of covariance to determine the effect of initial plant size on final measurements. Therefore, ANOVA was performed on the difference in measurements taken after one season of field growth (Nov. to Dec. 2010) and measurements taken before planting (Apr. 2010) and on the difference between the end of the first season and the end of the second season of field growth. With this analysis, we observed results similar to previous work with significantly greater increase in whole plant dry weight for 'Emerald' and 'Jewel' TC plants compared with SW regardless of the initial plant dry weight.

We observed that 8- and 14-month-old 'Emerald' and 'Jewel' TC plants had greater total shoot number than SW plants and after two growing seasons, tissue culture plants of all the cultivars tested had more canes than plants propagated from rooted cuttings. Previous work with 'Northblue' blueberry resulted in TC having more basal branches (canes) and lateral branches or shoots than plants from rooted cuttings during their first 3 years of field growth (Litwiñczuk et al., 2005; Read et al., 1989). Whether the increased branching observed in blueberry plants derived from TC compared with SW lasts for 1,2, or more years, it still poses a significant advantage during establishment years and can result in a greater number of flower buds per plant and greater early yields (Grout et al., 1986). The effect of propagation method on reproductive growth and yield and the relationship between shoot number and yield for the present trial is under evaluation and will be reported in a separate paper.

Despite differences in management practices between the two locations used in this study, the effect of propagation method on the three cultivars studied was, overall, similar in Citra than in HC. During the first season in the field, 'Emerald' and 'Jewel' TC plants tended to have greater plant canopy volume than SW plants, whereas the opposite was observed for 'Primadonna' (June to Nov. 2010). 'Emerald' and 'Jewel' TC plants had more major canes and plant dry weight after the first and second growing seasons with 
no significant effect of propagation type on plant dry weight or total shoot number for 'Primadonna' at any point during the study. Total shoots per plant were greater for TC 'Emerald' and 'Jewel' after one season in the field but only for 'Jewel' after two seasons compared with SW plants. The effect of propagation method on vegetative growth and field performance seems to be cultivar-dependent and more trials should be conducted in several locations with these and other southern highbush blueberry cultivars before general recommendations can be made.

\section{Literature Cited}

Albert, T., M. Starast, K. Karp, H. Kaldmae, E. Vool, and T. Paal. 2009. The influence of propagation method on growth of the half-highbush blueberry 'Northblue'. Acta Hort. 812:141146.

Cochran, W.G. 1957. Analysis of covariance: Its nature and uses. Biometrics 13:261-281.

Darnell, R.L. and F.S. Davies. 1990. Chilling accumulation, budbreak, and fruit set of young rabbiteye blueberry plants. HortScience 25:635638.

Debnath, S.C. 2007. Propagation of Vaccinium in vitro. Intl. J. Fruit Sci. 6:47-71.

Elashoff, J.D. 1969. Analysis of covariance: A delicate instrument. Amer. Educ. Res. J. 6:383-401.

Fall Creek Farm and Nursery. 2014. Southern highbush. Low chill varieties. 2 Feb. 2014. $<$ http://www.fallcreeknursery.com/commercial/ variety/commercial_southern-highbush>.
Ferguson, J.J., P.C. Andersen, J.X. Chaparro, and J.G. Williamson. 2008. Florida subtropical peaches: General concepts and cultivars recommended for grower trial. University of Florida Coop. Ext Serv., Gainesville. Publ. HS1125.

Grout, J.M., P.E. Read, and D.K. Wildung. 1986. Influence of tissue culture and leaf-bud propagation on the growth habit of 'Northblue' blueberry. J. Amer. Soc. Hort. Sci. 111:372-375.

Gustavsson, B.A. and V. Stanys. 2000. Field performance of 'Sanna' lingonberry derived by micropropagation vs. stem cuttings. HortScience 35:742-744.

Jamieson, A.R. and N.L. Nickerson. 2003. Field performance of lowbush blueberry propagated by seed, stem cuttings and micropropagation. Acta Hort. 626:431-436.

Isutsa, D.K. and M.P. Pritts. 1994. Rapid propagation of blueberry plants using ex vitro rooting and controlled acclimatization of micropropagules. HortScience 29:1124-1126.

Littell, R.C., W.W. Stroup, and R.J. Freund. 2002. SAS for linear models. 4th Ed. SAS Institute. A two way factorial experiment. p. 74-80. 11 Nov. 2013. <http://books.google.com/books? id $=$ JhxKC8ewcdAC\&dq $=$ slicing + proc + glm \& source $=$ gbs_navlinks_s $>$.

Litwiñczuk, W., G. Szczerba, and D. Wrona. 2005 Field performance of highbush blueberries (Vaccinium corymbosum L.) cv. 'Herbert' propagated by cuttings and tissue culture. Sci. Hort. 106:162-169.

Lyrene, P.M. 1980. Micropropagation of rabbiteye blueberries. HortScience 15:80-81.

Lyrene, P.M. 1981. Juvenility and production of fast-rooting cuttings from blueberry shoot cultures. J. Amer. Soc. Hort. Sci. 106:396-398.
Miller, S.A., E.K. Rawnsley, J. George, and N. Patel. 2004. A comparison of blueberry propagation techniques used in New Zealand. Acta Hort. 715:397-402.

NASA. 2010. National Aeronautics and Space Administration. 28 Jan. 2014. <http://www. grc.nasa.gov/WWW/BGH/volume.html>.

Read, P.E., C.A. Hartley, J.G. Sandahl, and D.K Wildung. 1988. Field performance of in vitro propagated blueberries. Proc. Intl. Plant Prop. Soc. 37:450-452.

Read, P.E., D.K. Wildung, and C.A. Hartley. 1989. Field performance of in vitro-propagated 'Northblue' blueberrries. Acta Hort. 241:191194.

Smolarz, K. and D. Chlebowska. 1997. Growth, vigour and yielding of highbush blueberry $\mathrm{cv}$. Bluecrop propagated from semi-woody cuttings and in vitro. J. Fruit Ornment. Fruit Res. 5:53-60.

Strik, B. and G. Buller. 2005. The Impact of early cropping on subsequent growth and yield of highbush blueberry in the establishment years at two planting densities is cultivar dependant HortScience 40:1998-2001.

Swartz, H.J., G.J. Galletta, and R.H. Zimmerman 1983. Field performance and phenotypic stability of tissue culture-propagated thornless blackberries. J. Amer. Soc. Hort. Sci. 108:285290.

Williamson, J.G., P.H. Harmon, O.E. Liburd, and P. Dittmar. 2013. Florida blueberry integrated pest management guide. Univ. of Florida Coop. Ext. Serv. Publ. HS1156.

Williamson, J.G. and D.S. NeSmith. 2007. Evaluation of flower bud removal treatments on growth of young blueberry plants. HortScience 42:571-573. 
Supplemental Table 1. $P$ values from analysis of variance for plant volume in 2010 .

\begin{tabular}{lrrrrr}
\hline \multicolumn{1}{c}{ Source } & \multicolumn{1}{c}{ June } & \multicolumn{1}{c}{ July } & August & September & October \\
\hline REP(LOC) & 0.9742 & 0.5310 & 0.7495 & 0.9378 & November \\
CV & $<0.0001$ & $<0.0001$ & $<0.0001$ & $<0.0001$ & 0.7602 \\
PROP & $<0.0001$ & 0.0001 & 0.8302 & 0.1675 & $<0.0001$ \\
CV*PROP & $<0.0001$ & $<0.0001$ & $<0.0001$ & 0.0001 & 0.1326 \\
LOC & $<0.0001$ & $<0.0001$ & 0.0014 & $<0.0001$ & 0.0007 \\
LOC*CV & 0.0326 & 0.0292 & 0.0011 & $<0.0001$ \\
LOC*PROP & 0.2257 & 0.2827 & 0.4233 & 0.0001 \\
LOC*CV*PROP & 0.3728 & 0.2625 & 0.6242 & 0.1458 & 0.000001 \\
\hline
\end{tabular}

$\mathrm{REP}(\mathrm{LOC})=$ replication, within each location; $\mathrm{CV}=$ cultivar; $\mathrm{PROP}=$ propagation; $\mathrm{LOC}=$ location.

Supplemental Table 2. $P$ values from analysis of variance for plant volume in 2011.

\begin{tabular}{lrrrrr}
\hline Source & \multicolumn{1}{c}{ June } & \multicolumn{1}{c}{ July } & August & September & October \\
\hline REP(LOC) & $<0.0001$ & $<0.0001$ & 0.0037 & 0.0700 & November \\
CV & 0.1393 & 0.0042 & 0.0015 & 0.0003 & 0.0072 \\
PROP & 0.0002 & 0.0034 & 0.0046 & 0.0243 & $<0.0001$ \\
CV*PROP & 0.0008 & 0.0015 & 0.0112 & 0.0281 & 0.0496 \\
LOC & $<0.0001$ & 0.0005 & 0.5407 & 0.0065 & 0.0195 \\
LOC*CV & 0.0174 & 0.0540 & 0.0038 & 0.0099 & 0.0002 \\
LOC*PROP & 0.1858 & 0.2239 & 0.7933 & 0.0047 \\
LOC*C*PROP & 0.0051 & 0.0200 & 0.0317 & 0.8702 & 0.4404 \\
\hline
\end{tabular}

$\mathrm{REP}(\mathrm{LOC})=$ replicate, within each location; $\mathrm{CV}=$ cultivar; $\mathrm{PROP}=$ propagation; $\mathrm{LOC}=$ location. 